\title{
Intronic cleavage and polyadenylation regulates gene expression during DNA damage response through U1 snRNA
}

\author{
Emral Devany ${ }^{1,3, *}$, Ji Yeon Park ${ }^{2,4, *}$, Michael R Murphy ${ }^{1, *}$, George Zakusilo ${ }^{1}$, Jorge Baquero ${ }^{1}$, \\ Xiaokan Zhang ${ }^{1}$, Mainul Hoque ${ }^{2}$, Bin Tian², Frida E Kleiman ${ }^{1}$
}

${ }^{1}$ Chemistry Department, Belfer Research Building, Hunter College and Graduate Center, City University of New York, New York, NY, USA; ${ }^{2}$ Department of Microbiology, Biochemistry and Molecular Genetics, Rutgers New Jersey Medical School, Newark, NJ, USA

The DNA damage response involves coordinated control of gene expression and DNA repair. Using deep sequencing, we found widespread changes of alternative cleavage and polyadenylation site usage on ultraviolet-treatment in mammalian cells. Alternative cleavage and polyadenylation regulation in the $3^{\prime}$ untranslated region is substantial, leading to both shortening and lengthening of $3^{\prime}$ untranslated regions of genes. Interestingly, a strong activation of intronic alternative cleavage and polyadenylation sites is detected, resulting in widespread expression of truncated transcripts. Intronic alternative cleavage and polyadenylation events are biased to the $5^{\prime}$ end of genes and affect gene groups with important functions in DNA damage response and cancer. Moreover, intronic alternative cleavage and polyadenylation site activation during DNA damage response correlates with a decrease in U1 snRNA levels, and is reversible by U1 snRNA overexpression. Importantly, U1 snRNA overexpression mitigates ultraviolet-induced apoptosis. Together, these data reveal a significant gene regulatory scheme in DNA damage response where U1 snRNA impacts gene expression via the U1-alternative cleavage and polyadenylation axis.

Keywords: alternative polyadenylation; DNA damage response; U1 snRNP

Cell Discovery (2016) 2, 16013; doi:10.1038/celldisc.2016.13; published online 14 June 2016

\section{Introduction}

Almost all eukaryotic mRNA precursors undergo a co-transcriptional modification at the $3^{\prime}$ end, which includes two coupled steps, cleavage and polyadenylation $[1,2]$. Cleavage/polyadenylation $(\mathrm{C} / \mathrm{P})$ involves recognition of upstream and downstream cis

\footnotetext{
*These authors contributed equally to this work.

${ }^{3}$ Current address: Department of Biological Sciences, Kingsborough Community College, City University of New York, New York, NY 11235 , USA.

${ }^{4}$ Current address: Division of Biomedical Informatics, Seoul National University College of Medicine, Seoul 03080, Republic of Korea. Correspondence: Bin Tian

Tel: +1-973-972-3615; Fax: 1+973-972-2668;

E-mail: btian@rutgers.edu.

Frida E Kleiman

Tel: +1-212-896-0451; Fax: +1-212-772-5332;

E-mail: fkleiman@hunter.cuny.edu

Received 3 November 2015; accepted 7 March 2016
}

elements around the $\mathrm{C} / \mathrm{P}$ site (known as $\mathrm{pA}$ ) by the $\mathrm{C} / \mathrm{P}$ complex [3, 4]. While a relatively simple signal sequence in the precursor mRNA is required for the reaction, many interactions between a large number of protein factors are necessary for the correct formation of the $\mathrm{C} / \mathrm{P}$ complex [3]. In addition to factors in the core $\mathrm{C} / \mathrm{P}$ complex, it has been shown that splicing factors can play roles in $3^{\prime}$ end processing. U1 snRNP (or U1) has been implicated in inhibition of $\mathrm{C} / \mathrm{P}$ via poly(A) polymerase [5-7]. This mechanism has recently been suggested to play a key role in controlling transcript length $[8,9]$. In addition, U2 snRNP factors have been shown to interact with core C/P factors [10].

Well over half of the mammalian genes contain more than one $\mathrm{pA}$, leading to expression of alternative cleavage and polyadenylation (APA) isoforms [11]. APA is highly dynamic across tissue types $[12,13]$, in cell proliferation and differentiation [14, 15], and in response to extracellular cues [16]. Most APA sites are 
located in the $3^{\prime}$ untranslated region (3'UTR) of mRNA [17]. As 3'UTRs contain various cis elements for post-transcriptional control, such as microRNA target sites and AU-rich elements, 3UTR-APA can significantly impact mRNA metabolism. In addition, a sizable fraction of genes harbor pAs in introns [17]. Intron-APA can result in change of coding sequences of mRNA, impacting the proteome. The core mammalian $\mathrm{C} / \mathrm{P}$ machinery and additional cis elements around the $\mathrm{pA}$ are responsible for the selection among APA sites [18-20]. Interestingly, in keeping with U1's role in $\mathrm{C} / \mathrm{P}$, recent studies have shown that inhibition of U1 function leads to activation of intron-APA events, resulting in shorter transcripts $[8,21]$.

The DNA damage response (DDR) occurs on a number of environmental exposures, such as ultraviolet (UV) irradiation, and involves functional and structural changes in a number of nuclear proteins, resulting in a coordinated control of gene expression and DNA repair. One key aspect of the response is the transient decrease of the cellular levels of mRNA following UV irradiation and its recovery [22, 23]. Although the mechanisms involved in this response are still not completely resolved, it has been determined that the UV-induced inhibition of both transcription [24] and mRNA $3^{\prime}$ processing [25] are responsible for the decrease in mRNA levels. Both $3^{\prime}$ end formation and transcription are affected in a similar time frame after DNA damage, resulting in a general, transient decrease of the cellular levels of polyadenylated transcripts [25]. mRNA levels of genes involved in DDR appear to be specifically regulated at the 3 '-end processing step [26]. Tumor suppressors and DNA repair factors whose expression is commonly compromised in most cancers, such as BARD1 and p53, have functional interactions with the $3^{\prime}$ end processing factor CstF-50 and PARN deadenylase, resulting in the regulation of mRNA 3 processing during DDR [25, 27-33]. In addition, we have found that PARN deadenylase has a role in decreasing the levels of short-lived mRNAs involved in the regulation of cell growth, differentiation and DDR, and keeping their expression levels low under non-stress conditions [30, 33]. The existence of redundant mechanisms to control mRNA steady-state levels during DDR highlights the importance of the transcription/RNA processing machineries in this response.

Here we explore the mechanisms and consequences of APA on UV-induced DNA damage. Using 3' region extraction and deep sequencing (3READS), we show widespread changes of intron-APA and 3UTR-APA on UV treatment in mammalian cells. Distinct APA changes at different time points after UV treatment affect many genes involved in DDR and cancer. Intron-APA upregulation correlates with a decrease in U1 snRNA levels after UV-induced DNA damage. Importantly, overexpression of U1 snRNA reverses UV-induced intron-APA and mitigates the apoptosis caused by UV. Our results indicate that the U1-APA axis is an important part of gene regulatory mechanism in DDR.

\section{Results}

\section{Analysis of $U V$-induced APA by $3^{\prime} R E A D S$}

Previous studies indicated that $3^{\prime}$ end processing is regulated during DDR [25, 27-33]. To examine how APA is modulated in DDR, we treated colon carcinoma RKO cells with UV irradiation, followed by recovery for either 0.5 or $2 \mathrm{~h}$. To determine whether the effect of UV treatment on APA was general or specific to certain genetic background, we included in our study RKO-E6 (low p53 levels) cell line, which is isogenic to the RKO cell line. To mitigate the effect of differential regulation of APA isoforms through mRNA decay in cytoplasm and in keeping with our previous work to study functional effect of DNA damage using nuclear RNA and factors [30-34], nuclear RNA was extracted and subjected to 3 READS (Figure 1a), a recently developed deep sequencing method for analysis of APA isoform expression genome wide [17]. We examined relative expression of APA isoforms that used pAs in the 3'-most exon, which typically have different 3UTRs, as well as intronic pAs, which have different coding sequences and 3'UTRs (Illustrated in Figure 1b).

To simplify the analysis of APA in 3'-most exons, where a variable number of pAs can exist [11], we selected top two 3'UTR-APA isoforms for each gene with the most number of reads and examined their relative expression. For RKO cells, we identified 1278 and 1317 genes that displayed isoform expression changes in the $0-0.5 \mathrm{~h}$ and $0.5-2 \mathrm{~h}$ time windows, respectively (Fisher exact test, $P<0.05$; Figure 1c). For RKO-E6, we identified 728 and 755 genes with significant 3 UTR-APA changes in the $0-0.5 \mathrm{~h}$ and $0.5-2 \mathrm{~h}$ time windows, respectively (Figure 1d). The fact that fewer genes underwent 3UTR-APA in RKO-E6 cells than in RKO cells suggests a potential role of p53 in impacting the extent of 3UTR-APA regulation during DDR. Overall, for both cell lines, the number of genes which had upregulated distal pA isoform was similar to that of genes which had upregulated proximal pA isoform in both windows, indicating that there was no global direction for 
a

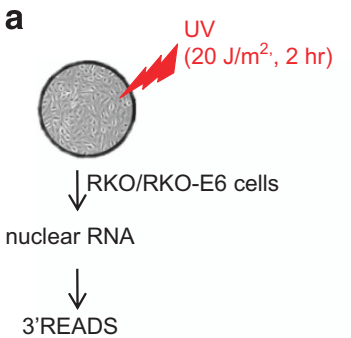

b

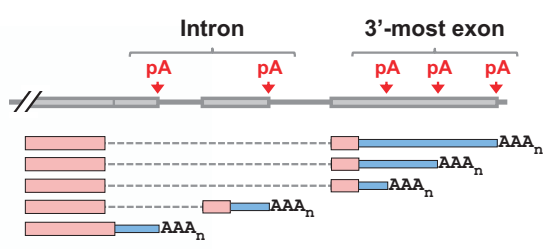

c
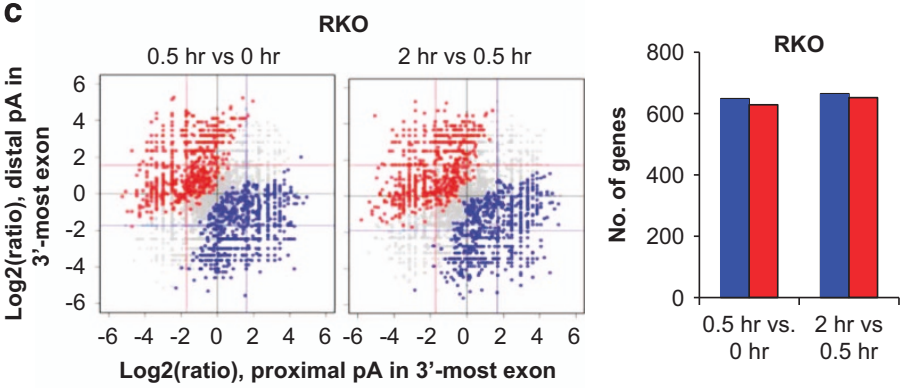

d
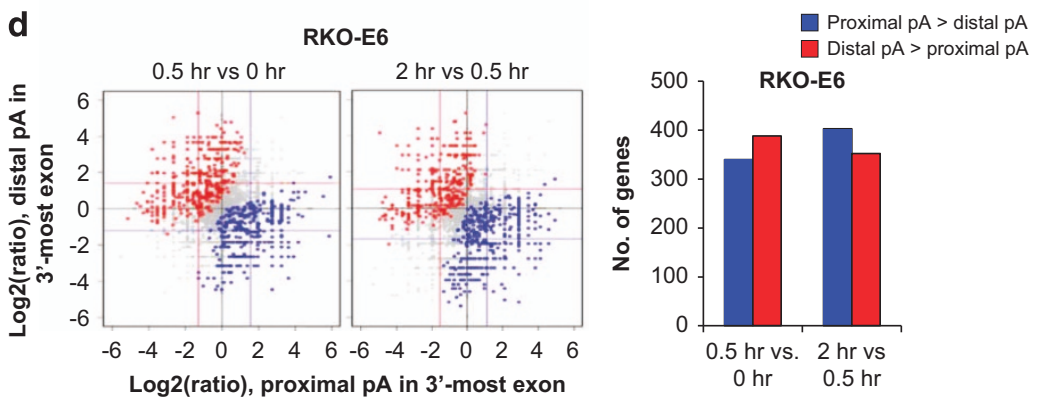
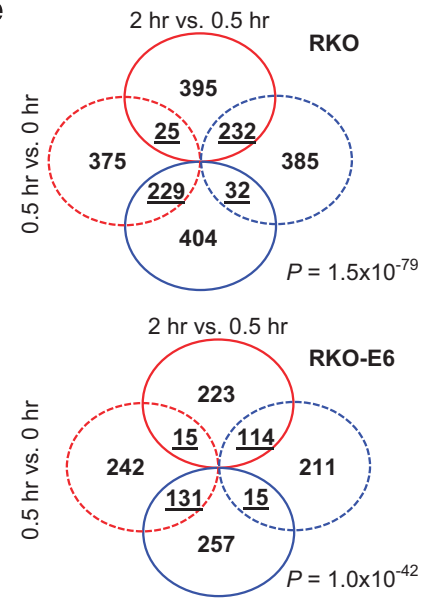

-- - Proximal pA > distal pA, $0.5 \mathrm{hr} v \mathrm{vs} \mathrm{hr}$

--- Distal pA > proximal pA, $0.5 \mathrm{hr} v \mathrm{vs} 0 \mathrm{hr}$

_ Proximal pA > distal pA, $2 \mathrm{hr}$ vs $0.5 \mathrm{hr}$

Distal pA > proximal pA, 2 hr vs $0.5 \mathrm{hr}$

Figure 1 Regulation of 3'UTR-APA in both RKO and RKO-E6 cells after UV treatment. (a) Experimental design for analysis of APA in UV-treated cells using 3'READS. (b) Schematic showing two types of APA examined in this study, namely intron-APA and 3'UTR-APA. (c, d) Comparison of 3'UTR-APA in RKO and RKO-E6 cells. Top 2 most abundant 3'UTR isoforms were chosen for each gene. Log2 ratios of expression are plotted between two isoforms. APA changes were examined in two time windows ( $0.5 \mathrm{vs}$ $0 \mathrm{~h}$, and 2 vs $0.5 \mathrm{~h}$ ) and considered significant when $P$-value $<0.05$ (Fisher's exact test). Blue dots represent genes with upregulated proximal pA isoform ( $3^{\prime} U T R$ shortened), and red dots represents genes with upregulated distal pA isoform ( $3^{\prime} U T R$ lengthened). Grey dots are genes that have no significant regulation. Colored lines indicate median values for blue or red dots. Number of genes with regulated $3^{\prime} U T R$ is shown on the right plot. Blue and red dots on the left correspond to genes in blue and red bars, respectively. (e) Venn diagram comparing significantly regulated 3'UTR-pA isoforms for both RKO and RKO-E6 cells. $P$-value (Fisher's exact test) indicates bias of distribution of the numbers in four overlapping areas (underlined). APA, alternative cleavage and polyadenylation; 3'READS, 3' region extraction and deep sequencing; UTR, untranslated region; UV, ultraviolet.

3'UTR length changes under these conditions. It is noteworthy that in both time windows and for both cells lines, upregulation of proximal pA isoforms was accompanied with a similar magnitude downregulation of distal pA isoforms and vice versa (similar $x$-axis and $y$-axis median values for blue and red dots in Figure 1c and $d$ ), indicating that APA isoform expression regulation was generally due to changes of $\mathrm{pA}$ choice rather than differences in isoform stability (which would cause different magnitudes of regulation).

Interestingly, the APA pattern in the $0-0.5 \mathrm{~h}$ window was largely different than the $0.5-2 \mathrm{~h}$ window for both cell lines (Figure 1e); a group of pAs in fact had an opposite regulatory trend between the two time windows. This result indicates widespread and dynamic 3UTR-APA regulation during the progression of DDR. Consistently, Gene Ontology (GO) analysis indicated that different biological processes were affected by 3UTR-APA in the two windows (Supplementary Table S1). For example, APA regulation was significantly enriched for genes associated with 'cell redox homeostasis', 'cellular homeostasis' and 'regulation of cellular component organization' in the $0.5-2.0 \mathrm{~h}$ window, whereas 'protein localization to endoplasmic reticulum', 'negative regulation of transport' and 'membrane 
a
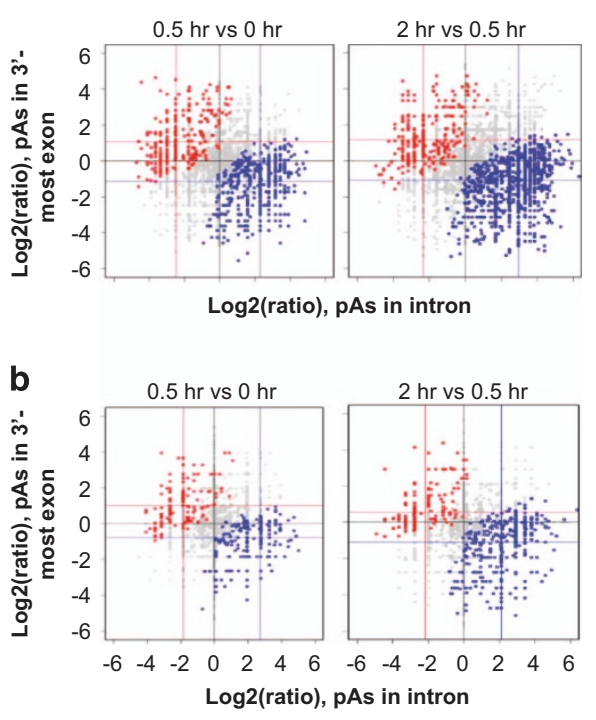

d

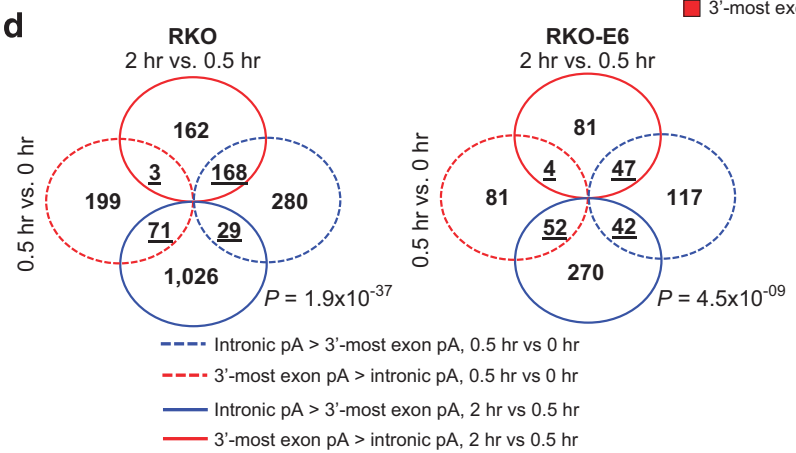

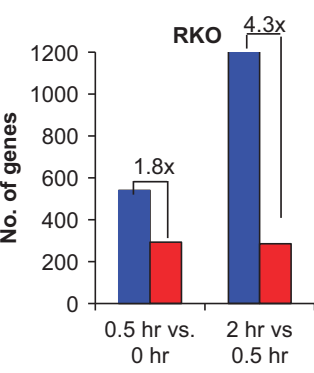
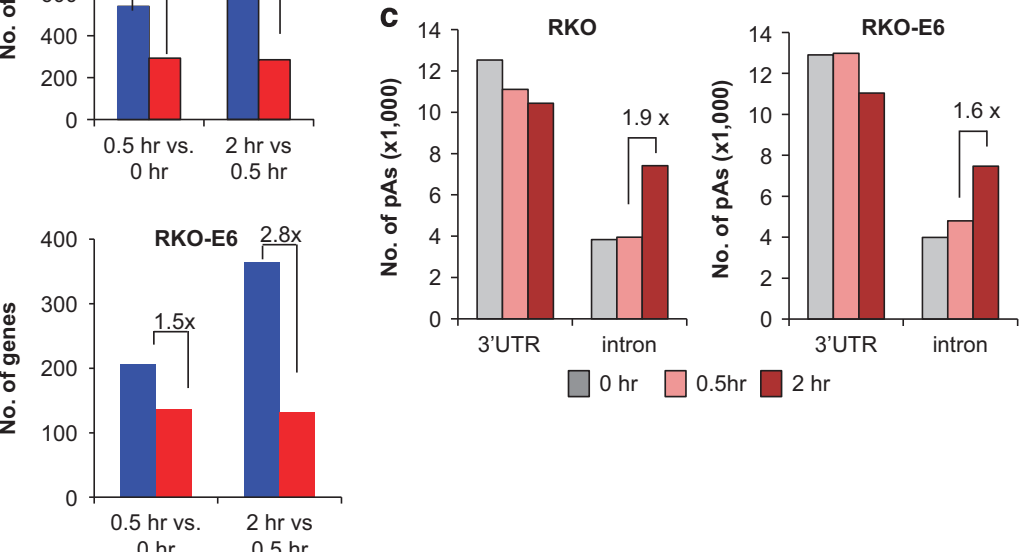

Figure 2 Regulation of intron-APA in both RKO and RKO-E6 cells after UV treatment. (a, b) Comparison of expression between intronic pA isoforms and all isoforms using pAs in the 3'-most exon in RKO and RKO-E6 cells. Blue dots correspond to genes with upregulated proximal $\mathrm{pA}$ isoform (intronic $\mathrm{pA}$ activation) and red dots correspond to genes with upregulated distal pA isoform (intronic $\mathrm{pA}$ repression). Grey dots are genes that have no significant regulation. Colored lines indicate median values for blue or red dots. Number of genes with significantly regulated intron-APA events is shown on the right. Ratio of number of genes in the blue bar to that of genes in the red bar is indicated. (c) Distribution of pAs detected in 3'UTRs or introns in samples from both RKO and RKO-E6 cells. Only pAs with read number greater than $5 \%$ of all reads of the gene were used. (d) Venn diagram comparing genes with significantly regulated intronic pA isoforms in two windows in samples from both RKO and RKO-E6 cells. (e) Venn diagram comparing significantly regulated APA events in RKO and RKO-E6 cells. Significance was determined by RED (relative expression difference), with the cutoff of $>1$ or $<-1$. (left) $3^{\prime} U T R-A P A$ events. (right) intron-APA events. Statistical analysis of overlapping genes was performed by the Fisher's exact test. APA, alternative cleavage and polyadenylation; $3^{\prime}$ READS, $3^{\prime}$ region extraction and deep sequencing; UTR, untranslated region; UV, ultraviolet.

protein proteolysis' were found to be associated with genes with APA regulation in the $0-0.5 \mathrm{~h}$ window. Three example genes are shown in Supplementary Figure S1.

A large fraction of human pAs are located in introns [35]. We next compared expression of isoforms using intronic pAs with those using 3'-most exon pAs for RKO and RKO-E6 cells. As with 3UTR-APA events, fewer genes underwent intron-APA in RKO-E6 cells than in RKO cells, suggesting a role of p53 in the regulation (Figure $2 \mathrm{a}$ and $\mathrm{b}$ ). Much to our surprise, intronic $\mathrm{pA}$ isoforms were greatly upregulated compared with 3'-most exon pA isoforms in both cell lines. This trend was much more conspicuous in the $0.5-2 \mathrm{~h}$ window than the $0-0.5 \mathrm{~h}$ window, in which $4.3-$ and 1.8-fold more genes had upregulated intronic $\mathrm{pA}$ isoforms than had upregulated 3'-most exon pA isoforms, respectively (Figure 2a). A similar trend was observed for RKO-E6 cells albeit to a lesser extent (2.8- and 1.5-fold, Figure 2b). In contrast to 3UTRAPA regulation, the magnitude of upregulation of intronic $\mathrm{pA}$ isoforms in both cell lines was greater than 
a

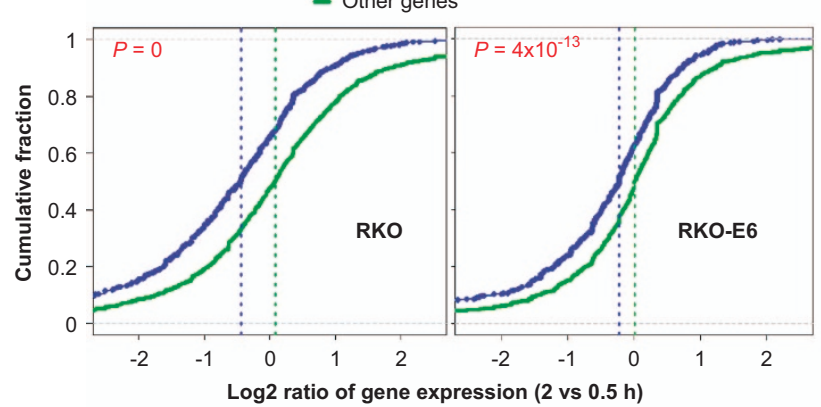

C

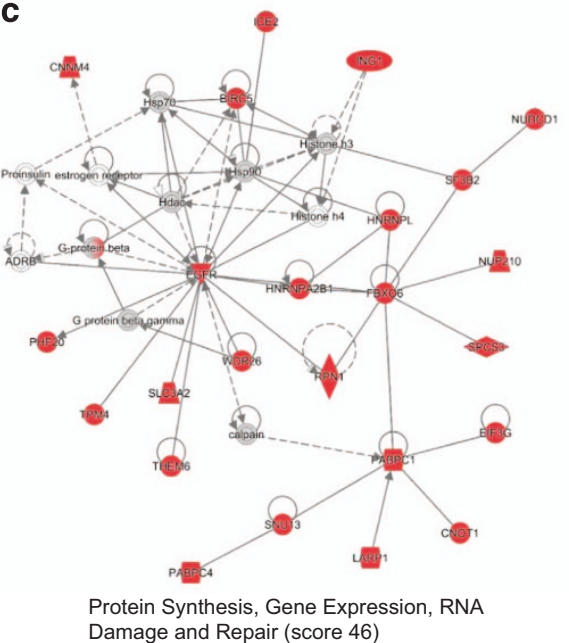

b

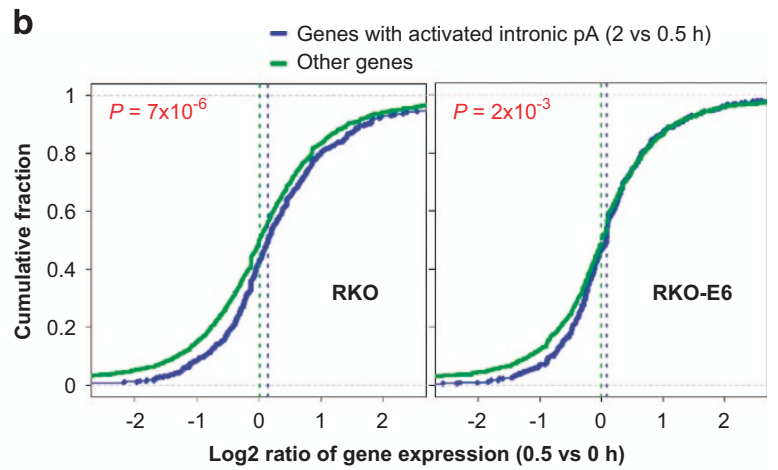

d

\begin{tabular}{ll}
\multicolumn{2}{c}{ Molecular and Cellular Function } \\
\hline Molecular and Cellular Function & p-value \\
\hline Cellular Movement & $4.9 \mathrm{E}-07$ \\
Cell Death and Survival & $1.4 \mathrm{E}-06$ \\
Cellular Development & $1.6 \mathrm{E}-05$ \\
Cellular Growth and Proliferation & $1.6 \mathrm{E}-05$ \\
Cellular Assembly and Organization & $3.9 \mathrm{E}-05$ \\
Cellular Function and Maintenance & $3.9 \mathrm{E}-05$ \\
Carbohydrate Metabolism & $6.1 \mathrm{E}-05$ \\
Cell Cycle & $6.1 \mathrm{E}-05$ \\
Cell Morphology & $6.1 \mathrm{E}-05$ \\
Protein Synthesis & $1.5 \mathrm{E}-04$ \\
Gene Expression & $1.7 \mathrm{E}-04$ \\
Cell-To-Cell Signaling and Interaction & $3.3 \mathrm{E}-04$ \\
Post-Translational Modification & $4.3 \mathrm{E}-04$ \\
Molecular Transport & $6.0 \mathrm{E}-04$ \\
Protein Trafficking & $6.0 \mathrm{E}-04$ \\
Free Radical Scavenging & $9.0 \mathrm{E}-04$ \\
DNA Replication, Recombination, and Repair & $9.0 \mathrm{E}-04$ \\
\hline
\end{tabular}

Figure 3 Relationship between intronic APA and gene expression regulation. (a) Gene expression changes vs intron-APA regulation. The blue line is for genes with activated intronic $p A$ in 2 vs $0.5 \mathrm{~h}(\mathrm{RED}<-1)$, and green line for other genes. $X$-axis indicates log2 ratio of gene expression in 2 vs $0.5 \mathrm{~h}$ in RKO (left) and RKO-E6 (right). Y-axis is cumulative fraction. The median value of each group is indicated by a dotted vertical line. The $P$-value is based on comparison of two groups using the Kolmogorov-Smirnov test. (b) As in a except that gene expression changes are based on $0.5 \mathrm{vs} 0 \mathrm{~h}$. Note that intronic regulation is based on 2 vs $0.5 \mathrm{~h}(\mathrm{RED}<-1)$ as in a. (c, d) Significant functional categories enriched with genes with significant intronic APA regulation in both RKO and RKO-E6 cells (underlined in the Venn diagram in Figure 2e, right panel), as analyzed by the Ingenuity Pathway Analysis Network (c) and Molecular and Cellular Function terms (d). In the network, red nodes indicate genes with significant intronic APA regulation. APA, alternative cleavage and polyadenylation.

that of downregulation of 3'-most exon pA isoforms (different $x$-axis and $y$-axis median values for blue and red dots in Figure 2a and b), in line with the fact that intronic pAs isoforms are typically expressed at much lower levels than 3UTR pA isoforms. Consistently, greater numbers of intronic pAs were detected in $2 \mathrm{~h}$ samples than in 0 or $0.5 \mathrm{~h}$ samples by 1.9 - and 1.6 -fold for RKO and RKO-E6, respectively (Figure 2c). Six example genes are shown in Supplementary Figure S2. Together, these results suggest that while p53 expression may impact the extent of APA regulation, it does not affect the direction of regulation.

Similar to the 3UTR-APA result, genes with regulated intronic pAs in the two time windows analyzed are largely different (Figure 2d). GO analysis
(Supplementary Table S2) indicated that upregulated intronic $\mathrm{pAs}$ in the $0-0.5 \mathrm{~h}$ window were enriched for genes associated with several GO terms, such as 'regulation of protein kinase B signaling cascade' and 'modification of morphology or physiology of other organism involved in symbiotic interaction', and those in the $0.5-2 \mathrm{~h}$ window were enriched for genes associated with 'regulation of transcription from RNA polymerase II promoter', 'response to DNA damage stimulus', 'nucleocytoplasmic transport' and so on. A significant number of regulated intronic APA events overlapped between RKO and RKO-E6 cells $\left(P=2.4 \times 10^{-5}\right.$, Fisher's exact test, Figure $2 \mathrm{e}$, right panel), suggesting that the effect of UV treatment on intronic APA is not cell type specific. Notably, the 
extent of overlap is greater than that for 3UTR-APA $(P=0.14$, Fisher's exact test, Figure 2e, left panel), suggesting that intron-APA is less regulated by p53 than is 3UTR-APA.

We then asked how intron-APA regulation was related to gene expression (Figure $3 a$ and b, Supplementary Figure S6). Our data indicate that genes with intronic pA activation between 0.5 and $2 \mathrm{~h}$ were more likely to be downregulated in the same period, as compared with other genes (Figure 3a), suggesting that intronic APA can inhibit gene expression by generating truncated transcripts. Interestingly, we also found that the same genes with intronic pA activation between 0.5 and $2 \mathrm{~h}$ were also more likely to be upregulated between 0 and $0.5 \mathrm{~h}$ after UV treatment (Figure $3 b$ ), suggesting that intronic APA might serve as a mechanism to regulate gene expression of factors involved in the response, such as POLR2A and cyclindependent kinase inhibitor 1A (CDKN1A), assuring that cells react to damage response in a controlled and timely manner. Consistent with this and the results shown in Supplementary Table S2, Ingenuity Pathway Analysis showed that genes with significant intronic APA regulation in both RKO and RKO-E6 cells were associated with pathways highly relevant to DDR (Figure $3 \mathrm{c}$ and $\mathrm{d}$ ).

\section{Validation of $U V$-induced APAs detected by $3^{\prime} R E A D S$}

To validate our genome-wide analysis, we examined 3UTR- and intron-APAs for genes following the strategies shown in Figure 4a. To further confirm that the effect of UV treatment on intronic APA is not a cell type-specific effect, we extended our study to colon carcinoma HCT116 cells. Briefly, after recovery from UV treatment, nuclear RNA was isolated from colon carcinoma HCT116 and RKO cells and complementary DNA (cDNA) was synthesized by reverse transcription using oligo(dT) primers. Quantitative reverse transcription-PCR (qRT-PCR) was performed with these cDNA as template. HCT116 results are shown in Figure $4 \mathrm{~b}$ and c. Three primers were used to detect intron-APA products (short isoform) and full-length mRNAs (long isoform): the forward primers were located in the upstream exons of regulated intronic pAs of studied genes and the two reverse primers corresponded to either the intron containing the pA (for detection of short isoform) or the downstream exon (for detection of long isoform). A similar strategy was used to detect 3'UTR-APA products: a common forward primer in the 3UTR and the two reverse primers corresponded to either upstream (for detection of total 3UTR-APA) or downstream (for detection of distal-APA isoforms) from the used $\mathrm{pA}$. The values for the proximal APA were calculated by subtracting the distal-APA values from the total 3'UTR-APA values.

As shown in Figure 4b, our analysis for 3UTR-APAs included genes involved in different biological pathways (Supplementary Table S1) with functions in DDR and cancer, such as small nuclear ribonucleoprotein polypeptide B (SNRPB2) [36, 37], endoplasmic reticulum protein retention receptor 1 (KDELR1) [38, 39]; Notch homolog 1 translocationassociated (NOTCH1) [40, 41] and dual specificity phosphatase 6 (DUSP6) [42, 43]. Consistent with the 3 READS results (Figure 1c), the analysis of UVinduced 3 UTR-APA in the $0-0.5 \mathrm{~h}$ window indicated that each individual gene did not show a major change in the distal/proximal ratio. However, UV treatment in the $0-2 \mathrm{~h}$ window induced changes in the usage of $\mathrm{pA}$ for individual genes, favoring either distal (KDELR1, NOTCH1 and DUSP6) or proximal (SNRPB2) pAs. The analysis shown in Figure 1c might represent the overall behavior of the total genes analyzed, indicating that there was no global direction of 3 UTR length changes under these conditions.

Our analysis for intron-APAs included genes with important functions in DDR and cancer (Figure 4c), namely cyclin-dependent kinase inhibitor $1 \mathrm{~A}$ (CDKN1A, p21) [44, 45], polymerase (RNA) II (DNA directed) polypeptide A (POLR2A, RNA polymerase II) $[46,47]$, Ephrin B2 (EFNB2) [48, 49], E2F transcription factor 1 (E2F1) [50, 51] and Down syndrome critical region gene 3 (DSCR3) [52, 53]. Importantly, based on IPA analysis, CDKN1A and POLR2A were at the hub of the networks significantly associated with intronic $\mathrm{pA}$ activation in the $0.5-2 \mathrm{~h}$ window (Supplementary Figure S3A and B). Consistent with the 3 READS analysis results, UV treatment induced the formation of intron-APA transcripts that were polyadenylated (Figure $4 \mathrm{~b}$ and $\mathrm{c}$ ). Interestingly, the increase in intron-APA isoforms was observed from 2 to $6 \mathrm{~h}$ after UV treatment, but these shorter isoforms decrease after $10 \mathrm{~h}$, reaching the levels of untreated cells (Figure 4c). Similar results were observed with RKO cells (not shown), suggesting that UV-mediated regulation of intronic APA is not a cell type-specific effect. The transient nature of these intron-APA isoforms is consistent with previously characterized responses to DNA damage [25, 30]. The sequences of the second intron was not detected in any of the mRNAs samples analyzed (Supplementary Figure S4A), indicating that intron-APA was induced within the first intron of the target mRNAs. Together, 
a
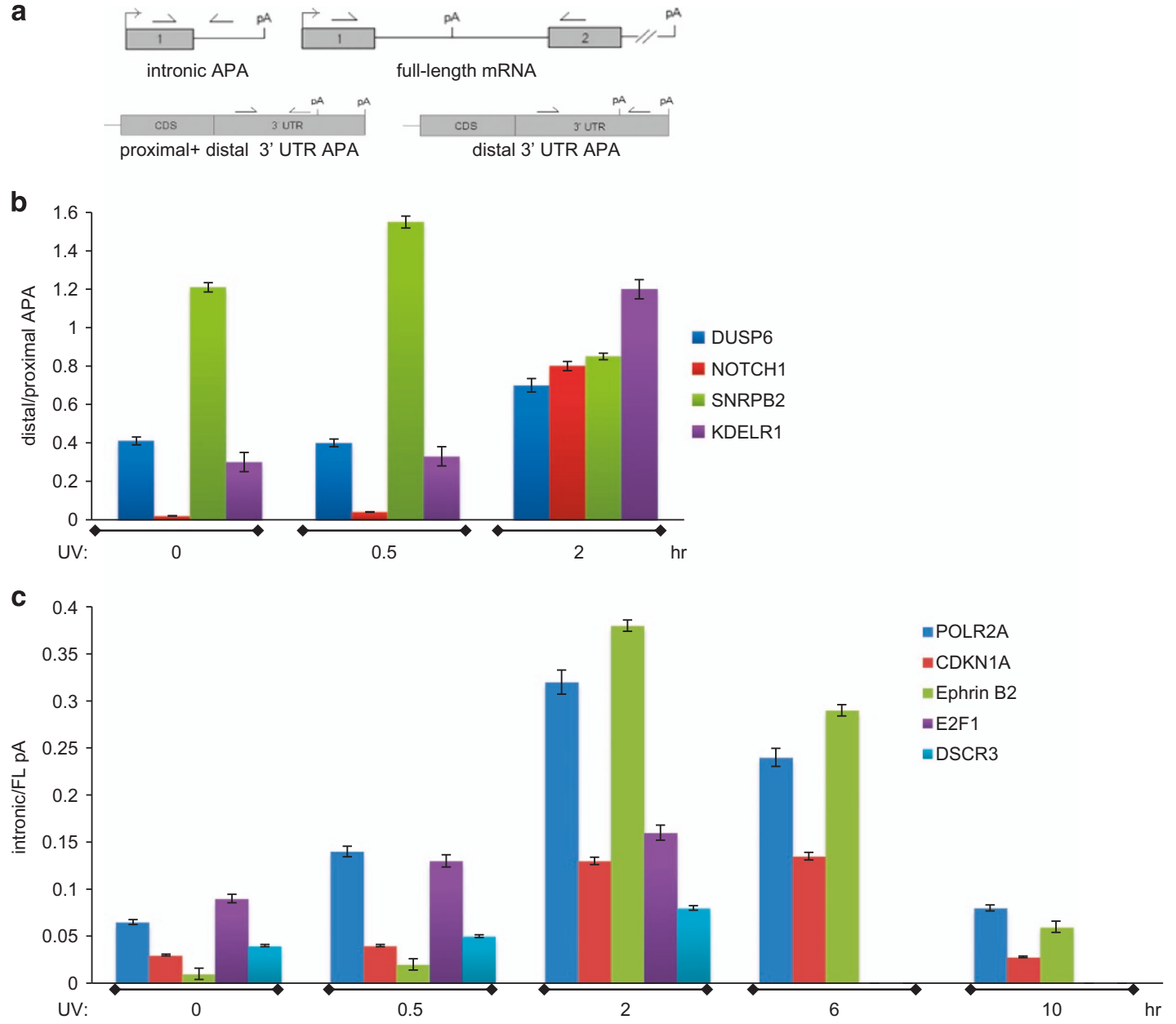

Figure 4 Effect of UV treatment on APA. (a) Schematic representation of amplified regions to detect 3'UTR and intronic APA. HCT116 were treated with UV irradiation and allowed to recover for indicated times, and then harvested. cDNA was prepared using oligo(dT) primers from nuclear RNA and used for PCR and qPCR reactions with primers specific for intronic APA, full-length mRNA, and 3'UTR (proximal and distal) APA. (b) qRT-PCR analysis of HCT116 samples for the effect of UV on 3'UTR pA choice. The ratio of distal/proximal of each analyzed gene is shown. Samples were prepared as described in a. The qRT-PCR values were calculated from three independent biological samples by triplicate. (c) Intron-APA is transiently upregulated on UV-induced DNA damage. Samples were analyzed as in a but the ratio of intronic/full-length of each mRNA is shown. The qRT-PCR values were calculated from three independent samples. APA, alternative cleavage and polyadenylation; cDNA, complementary DNA; qRT-PCR, quantitative reverse transcription-PCR; UV, ultraviolet.

these results indicate the UV treatment induce the usage of intronic pAs of genes involved in DDR, suggesting a possible role for these intron-APA events in controlling gene expression during the response.

\section{Features of $U V$-induced intronic APA events}

We next examined features of introns that harbor activated pAs in DDR in our 3READS data. Strikingly, we found the activated intronic pAs are highly enriched ( $>1.5$-fold above background) in 5 ' introns, with the most notable enrichment being pAs in the first intron in the $0.5-2 \mathrm{~h}$ window (2-fold above background) (Figure 5a). Consistently, we found that the distance from the activated pAs in the $0.5-2 \mathrm{~h}$ window to transcription start site (TSS) was significantly shorter than those in control cells $\left(P=3 \times 10^{-12}\right)$ (Figure 5b), a trend not seen for activated pAs in the $0-0.5 \mathrm{~h}$ window $(P=0.4)$. Further analysis of intron features indicated that introns harboring activated $\mathrm{pAs}$ are larger and had stronger $5^{\prime}$ splice site (5'SS) compared with other introns (Supplementary Figure S5). However, these distinct features were not significantly different from other first introns. Note that the upregulated intronic pAs of POLR2A and EFNB2 are both located in the first intron, and the APA event of CDKN1A was either in the first intron or 
a 5' intron depending on the TSS (Supplementary Figure S2). Interestingly, in addition to the sense strand pAs, we also noticed in the $0.5-2 \mathrm{~h}$ window a general upregulation of transcripts using pAs within
$4 \mathrm{~kb}$ from the TSS on the anti-sense strand (Figure 5c). These transcripts were previously named upstream anti-sense RNA (uaRNA) or PROMPTs [54, 55]. Their activation in the $0.5-2 \mathrm{~h}$ window suggests a

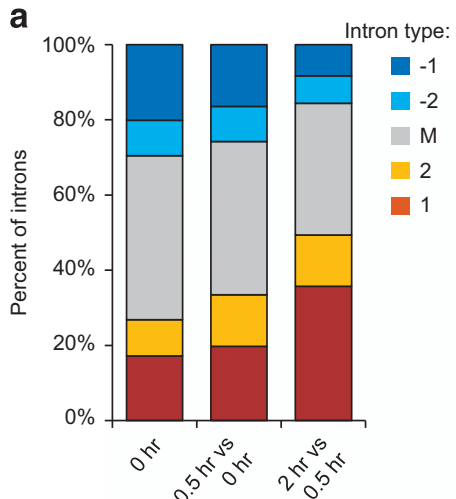

C
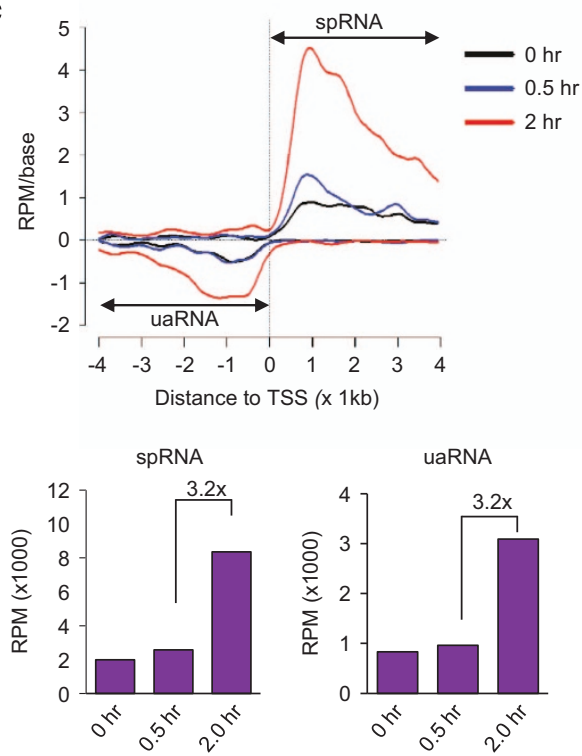

\begin{tabular}{|c|c|c|}
\hline \multicolumn{3}{|c|}{ Fold Change } \\
\hline Intron & $0.5 \mathrm{hr} v \mathrm{~s}$ & $2 \mathrm{hr} v \mathrm{~s}$ \\
\hline type & $0 \mathrm{hr}$ & $0.5 \mathrm{hr}$ \\
\hline-1 & -1.2 & -2.4 \\
\hline-2 & -1.1 & -1.4 \\
\hline$M$ & -1.1 & -1.2 \\
\hline 2 & 1.5 & 1.5 \\
\hline 1 & 1.2 & 2.0 \\
\hline
\end{tabular}

b

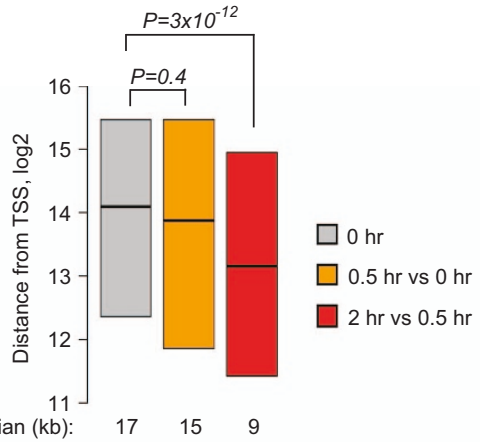

d
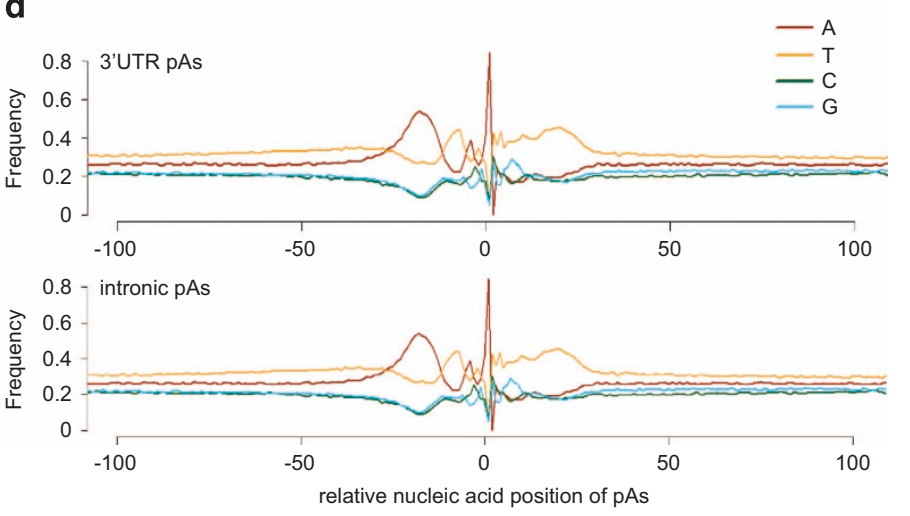

Figure 5 Regulation of intronic APA and C/P events around transcription start site (TSS) in response to UV. (a) Distribution of introns with activated pAs in genes. 1, first intron; 2 , second intron; $M$, middle introns; -2 , second to the last intron; -1 , last intron. Single introns were excluded from this analysis. The number of introns falling into multiple types, for example, both +1 and -1 types, was evenly divided in calculation. Introns with $\mathrm{pAs}$ at $0 \mathrm{~h}$ were used as control. Changes of percent of introns with activated pAs at 0.5 vs $0 \mathrm{~h}$ or 2 vs $0.5 \mathrm{~h}$ are shown in a table next to the plot. (b) Boxplot showing distance from the transcription start site (TSS) to intronic pAs. Only the 25th to 75th percentile values are shown. The $0 \mathrm{~h}$ data are based on all detected intronic pAs, and the 0.5 vs $0 \mathrm{~h}$ and 2 vs $0.5 \mathrm{~h}$ data are based on activated intronic pAs. $P$-values were based on Wilcoxon test comparing the 0.5 vs $0 \mathrm{~h}$ or 2 vs $0.5 \mathrm{~h}$ values with those of control $(0 \mathrm{~h})$. (c) Distribution of pAs around the TSS. Top panel: all detected pAs in three samples are plotted, and are shown as reads per million (RPM) per base. The pAs within $4 \mathrm{~kb}$ from the TSS on the anti-sense strand are called upstream anti-sense RNA (uaRNA) pAs, and those within $4 \mathrm{~kb}$ from the TSS on the sense strand are called sense proximal RNA (spRNA) pAs. For uaRNA pAs, we discarded pAs that were associated with any known genes, and for spRNA pAs we excluded pAs that were located in the 3'-most exon of genes. Bottom panel: the amounts of uaRNAs or spRNAs are shown in bar graphs. The ratio of transcript amount in the $2 \mathrm{~h}$ sample to that in the $0.5 \mathrm{~h}$ sample for spRNA pAs (top) or uaRNA pAs (bottom) is indicated. (d) Distribution of nucleotides as a function of base position around the pA identified by $3^{\prime} R E A D S$. The upstream and downstream regions around the pA were analyzed, spanning from - $100 \mathrm{nt}$ to $100 \mathrm{nt}$, with the pA set at $0 \mathrm{nt}$. The $y$-axis indicates frequency of each type of nucleotide at a given position. Top panel: nucleotide frequency around 3 'UTR pAs (14058 in total). Bottom panel: nucleotide frequency of intronic pAs (6750 in total). APA, alternative cleavage and polyadenylation; 3'READS, 3' region extraction and deep sequencing. 
a

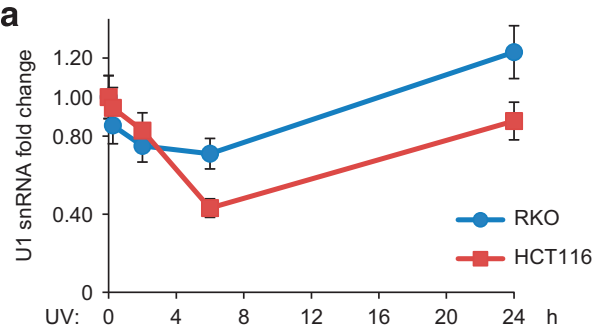

b

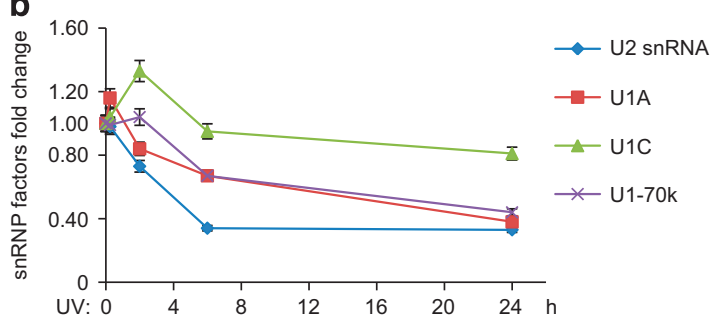

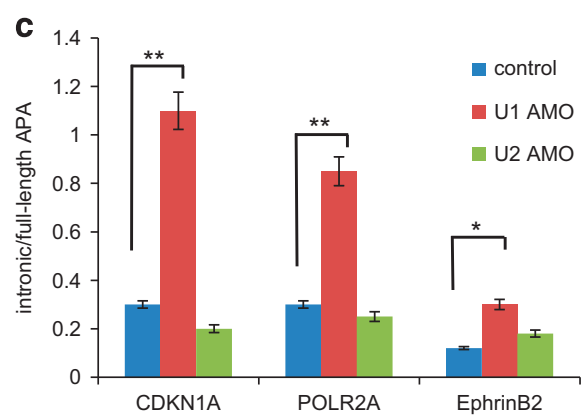
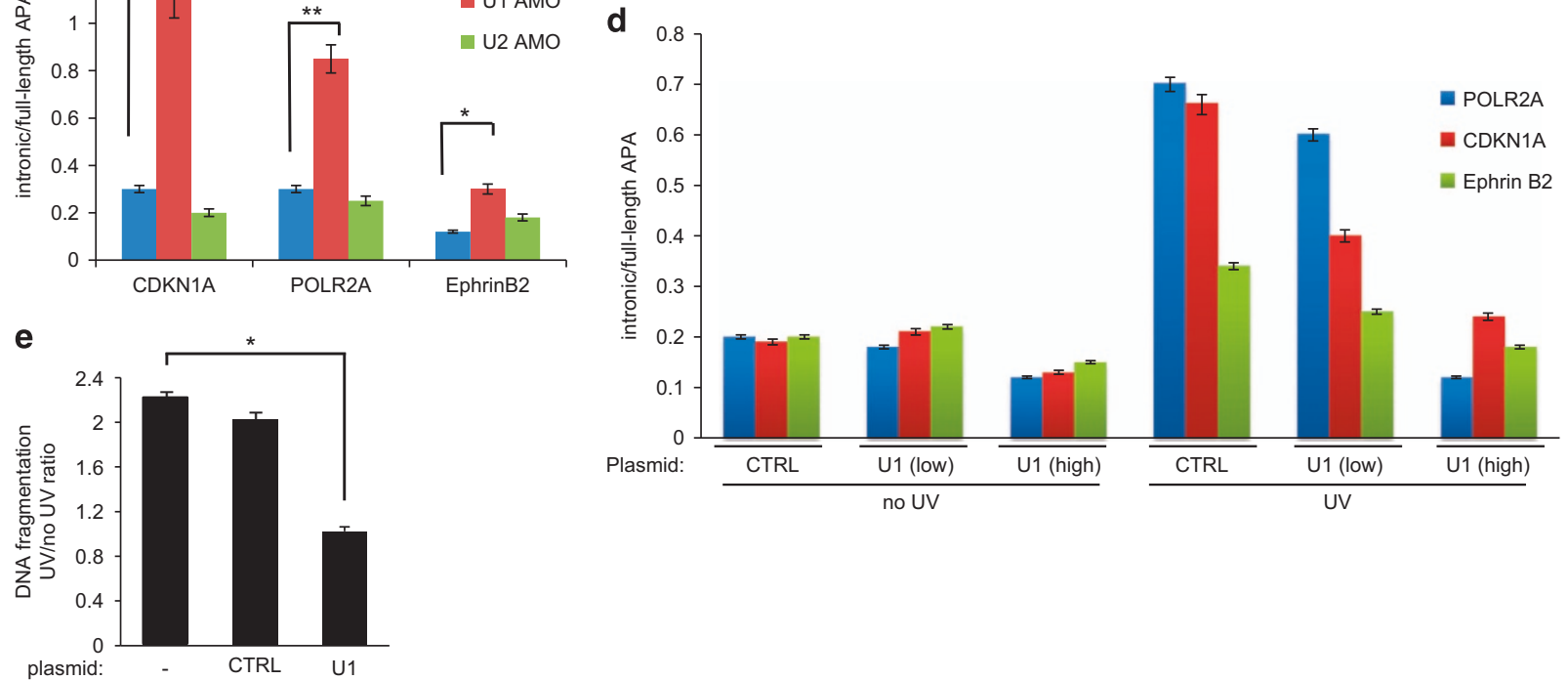

Figure 6 U1 RNA levels inversely correlate with intronic APA. (a) U1 snRNA levels decrease after UV treatment. HCT116 and RKO cells were treated with UV irradiation and allowed to recover for the indicated times, and then harvested. Nuclear RNA was isolated and cDNA was prepared using random primers. qRT-PCR reaction was performed with primers specific for U1 snRNA. qRT-PCR products of actin were used as endogenous control. The values from each sample were normalized to non-treated samples. The qRT-PCR values were calculated from three biological samples by triplicate in each determination. (b) Changes in the levels of spliceosome complex components on UV treatment. HCT116 cells were treated with UV irradiation and analyzed as in Figure $4 a$ by qRT-PCR reaction with primers specific for U2 snRNA, U1A, U1C and U1-70K. The qRT-PCR values were calculated from three independent samples. (c) Functional depletion of U1 snRNA, but not U2 snRNA, causes an increase in intronic PA. HCT116 cells were transfected with control or anti-sense morpholino targeting U1 snRNA (U1 AMO) or U2 snRNA (U2 AMO). cDNA was prepared and used in QRT-PCR assays as in Figure 4c. The qRT-PCR values were calculated from three biological samples were analyzed by triplicate in each determination. (d) Overexpression of U1 RNA abolishes UV-induced intronic APA. HCT116 cells were transfected with two concentrations of either control or U1 snRNA expressing vectors and treated with UV irradiation. Nuclear RNA was used to prepare cDNA, which was used in qRT-PCR reactions as in Figure 2b. The qRT-PCR values were calculated from three independent samples. (e) Overexpression of U1 RNA decreases the levels of UV-induced apoptosis in HCT116 cells. The DNA fragmentation was calculated from three independent samples. APA, alternative cleavage and polyadenylation; cDNA, complementary DNA; qRT-PCR, quantitative reverse transcription-PCR; UV, ultraviolet.

unique mechanism regulating RNAP II activity around the TSS in this phase of DDR response. We also determined the distribution of nucleotides around the 3'UTR and intronic pAs identified by 3'READS (Figure 5d). The base composition profiles upstream and downstream from the pA for these two groups of pAs were highly similar and consistent with those of known pAs [11], indicating that the 3UTR and intronic pAs detected by 3 READS were genuine pAs with similar surrounding cis elements.

\section{Role of U1 RNA levels in intronic APA events during $D D R$}

The activation of promoter-proximal pAs in 2 vs $0.5 \mathrm{~h}$ is reminiscent of APA regulation by $\mathrm{U} 1 \mathrm{snRNP}$ : functional depletion of U1 RNA shortens mRNAs due 
to usage of promoter-proximal cleavage and polyadenylation signals [9]. Earlier studies have shown a decrease in U1 and U2 small RNA levels in HeLa cells on UV treatment [56]. Therefore, we examined whether intronic APA was triggered by U1 RNA reduction in response to UV irradiation. First, we detected the effect of UV treatment on the levels of U1 RNA by qRT-PCR using HCT116 and RKO cells (Figure 6a). Cells were treated with UV irradiation and allowed to recover for the indicated time points. Consistent with the studies of Eliceiri and Smith [56], our qRT-PCR analysis of nuclear RNA samples from these cells showed a transient decrease in U1 RNA levels on UV treatment (Figure 6a). Although a decrease in U1 RNA was detected as early as $0.5 \mathrm{~h}$ after UV treatment, the lowest level of U1 RNA was observed $6 \mathrm{~h}$ after UV treatment for both cell lines. The levels of U1 RNA increased $24 \mathrm{~h}$ after UV treatment, reaching the levels of untreated cells. Extending those studies, we analyzed the levels of other components of the $\mathrm{U} 1$ and $\mathrm{U} 2$ snRNPs by qRT-PCR. After UV treatment, a decrease was also observed in U2 RNA, U1A and U1-70K mRNAs of U1 snRNP (Figure 6b). No significant changes were observed in U1C levels. Thus, among all the molecules examined, U1 snRNA levels (Figure 6a) correlated the best with the changes in intronic/ full-length APA levels (Figure 4c). Previous studies indicate that U1 snRNPs, such as U1A and U1-70K, are inhibitors of $3^{\prime}$ end processing and intronic APA (reviewed in 57). Our studies indicate that the decrease of these U1 snRNPs early in DDR might increase intronic APA. However, only U1 snRNA levels correlate with the decrease in intronic APA later in the response, suggesting that other components of U1 snRNP might not be at the rate-limiting level during DDR.

Importantly, functional depletion of U1 RNA using morpholino oligonucleotides increased significantly the ratio of intron/full-length APA isoforms for POLR2A, CDKN1A and EFNB2 (Figure 6c). Strikingly, using low concentrations of U1 snRNA AMO, the changes in the intronic/full-length ratio by U1 RNA depletion were similar in magnitude to that observed after UV treatment (compare Figures $4 \mathrm{~b}$ and $6 \mathrm{c}$ ). As previously described [9], we did not detect sequences of the second intron in any of the mRNA samples analyzed at low concentrations of U1 snRNA AMO (Supplementary Figure S4B), indicating that the moderate functional decrease in U1 levels was insufficient to inhibit splicing. However, at higher concentrations, second intron inclusion was observed for the genes analyzed (Supplementary Figure S4B). U2 RNA depletion using morpholino did not increase the usage of examined intronic pAs (Figure 6c). This is consistent with previous studies showing that decrease of U2 snRNP levels has a different impact on intronic APA [21]. Supporting these results, overexpression of U1 snRNA reverses the UV-induced increase of intron-APA (Figure 6d) and apoptosis (Figure 6e). Together, these results indicate that the UV-induced downregulation of U1 snRNA, not other components of the U1 snRNP, is chiefly responsible for the activation of intronic APA sites during DDR.

\section{Discussion}

Here we report significant activation of intronic pAs on UV treatment in mammalian cells, adding a new layer of gene regulation in the cellular response to UV-induced DNA damage. At the center of this mechanism is U1 snRNA, one of the component of U1 snRNP, which has previously been shown to play an important role not only in splicing but also in $3^{\prime}$ end processing $[5,20]$. Our data for the first time provides a cellular response/pathway that is affected by the U1-APA axis and shows that downregulation of the U1 snRNA level is the controlling step for intronic APA in DDR. This mechanism results in activation of pAs located near TSS, mostly in the first intron, and serves as a rapid (within $2 \mathrm{~h}$ after UV) strategy to regulate expression of affected genes. Given the different correlations between intronic $\mathrm{pA}$ activation and gene expression changes in 0.5 vs $2 \mathrm{~h}$ and 0 vs $0.5 \mathrm{~h}$ windows, it is plausible that this mechanism assures that the expression of factors involved in the response, such POLR2A and CDKN1A, occurs in a controlled and timely manner. Consistent with this, genes with significant intronic APA regulation belong to pathways activated during DDR and downregulation of gene expression was more likely to be associated with intronic APA.

Our results indicate that similar changes in APA events occur in different cell lines in a similar timeframe, suggesting that UV-mediated regulation of intronic APA and 3UTR-APA are not a cell typespecific effect. However, our results also indicate that p53 expression may impact the extent of APA regulation during DDR. This is not surprising given that $\mathrm{p} 53$ is involved in different aspects of gene expression regulation during DDR, such as controlling transcription, mRNA stability and/or translation [58, 59]. Further experiments are needed to reveal the exact role of $\mathrm{p} 53$ in APA regulation in DDR. 
Although transcriptional and protein level changes of POLR2A and CDKN1A are known mechanisms of UV response in mammalian cells, the UV-induced regulation of their APA isoforms and steady-state levels of their transcripts have never been reported. A fraction of the largest subunit of POLR2A decreases by DNA damage-induced ubiquitination followed by proteasomal degradation in mammalian cells $[60,61]$. This modification can be detected within 15 min after exposing cells to UV irradiation and persists for about $8-12 \mathrm{~h}$ [60]. POLR2A ubiquitination requires C-terminal domain phosphorylation, which is a characteristic of elongating POLR2A [61, 62]. Interestingly, the polyadenylation factor CstF associated to the tumor suppressors BRCA1/BARD1 play a role in the proteasome-mediated degradation of POLR2A during DDR [27, 63]. Both the interaction of CstF and BRCA1/BARD1 complex $[24,27,31]$ and the proteasome-mediated degradation of POLR2A [27, 63] contribute to the inhibition of $3^{\prime}$ end processing that occurs after DNA damage. Those studies suggested the existence of several, possibly redundant, mechanisms to explain the inhibitory effect of UV irradiation on mRNA 3' processing. The studies presented here add another level of complexity indicating that the UV-induced decrease in POLR2A protein levels might be due to intronic APA, which results in a decrease in full-length POLR2A mRNA, supporting the idea that U1 snRNA plays a role in this response. The cellular function of this shorter form of POLR2A protein in cellular transcription as well as other factors involved in intronic APA during DDR will be addressed in future studies. Notably, it has been shown that UV damage switches the usage of pAs from the proximal to the distal one in the 3UTR for the yeast largest subunit of POLR2A gene [64]. How APA-medicated regulatory mechanisms vary in different species is another subject of future investigation.

Although it is known that a differential regulation of genes involved in DDR occurs during the progression of DDR, the mechanisms driving this differential regulation are not completely understood. One example is the p53 pathway. Although p53 binds to the promoter of all of its target genes not all these genes are activated with same stimulus at the same time of the response [65-67]. For example, while UV treatment induces $\mathrm{p} 53$ binding at the CDKN1A promoter, it does not induce a strong increase in CDKN1A levels of fulllength mRNA and protein [67]. However, p53 can activate CDKN1A expression under cell cycle arrest conditions induced by doxorubicin or Nutlin-3 treatment, indicating that other mechanisms contribute to the regulation of CDKN1A mRNA levels on UV treatment. Previous studies have shown that this stimulus specific response is regulated by posttranslational modifications of p53 [68, 69], p53-binding factors [70, 71], chromatin structure and transcription factors [61]. This suggests that multiple mechanisms contribute to define p53-dependent transcriptional profiles. Our studies indicate that activation of intronAPA and accumulation of shorter mRNA isoforms of CDKN1A might provide an alternative explanation of CDKN1A regulation during UVC-induced DNA damage.

Together, our study reveals a significant genespecific regulatory scheme in DDR where U1 snRNA impacts gene expression via APA.

\section{Materials and Methods}

\section{Tissue culture methods}

RKO, RKO-E6 and HCT116 cell lines were cultured in Eagle's minimal essential medium and Dulbecco's modified Eagles medium, respectively. Media were supplemented with $10 \%$ fetal bovine serum and $1 \%$ penicillin/streptomycin antibiotic.

\section{DNA-damaging agents}

Ninety percent confluent cultures were exposed to UV and harvested at the indicated times. UVC doses $\left(40 \mathrm{~J} \mathrm{~m}^{-2}\right)$ were delivered in two pulses using a Stratalinker (Stratagene, La Jolla, CA, USA). Prior to pulsing, medium was removed and replaced immediately after treatment.

\section{$3^{\prime} R E A D S$}

Colon carcinoma RKO cells were treated with UV irradiation and allowed to recover for 0.5 or $2 \mathrm{~h}$. Nuclear RNA was purified using the RNeasy kit (Qiagen, Valencia, CA, USA) following manufacturer's protocol, followed by 3'READS analysis as described in ref. 33. Briefly, after RNA fragmentation, poly(A)-containing RNA fragments were captured onto magnetic beads coated with a chimeric oligonucleotide (oligo $\mathrm{CU}_{5} \mathrm{~T}_{45}$ ), which contained 45 thymidines (Ts) at the $5^{\prime}$ portion and 5 uridines (Us) at the $3^{\prime}$ portion, and were released from the beads by RNase $\mathrm{H}$ treatment, which also eliminated most of the As of the poly(A) tail. Eluted RNA was ligated to $5^{\prime}$ and $3^{\prime}$ adapters, followed by reverse transcription, PCR amplification and deep sequencing.

\section{Data analysis}

Reads from 3 READS were aligned to the genome using Bowtie2 [72], and those with at least two non-genomic As at the $3^{\prime}$ end were considered as PolyA site-supporting reads, which were used for APA analysis. We used the Fisher's exact test to compare isoform expression between two samples. For 3UTRAPA analysis, the two most abundant 3 UTR pA isoforms were compared; for intron-APA analysis, we either compared each intronic $\mathrm{pA}$ isoform with all isoforms using $\mathrm{pAs}$ in the $3^{\prime}$-most 
exon or combined all intronic pA isoforms and compared them with all isoforms using pAs in the 3'-most exon. We used $P$-value $<0.05$ and relative abundance change $>5 \%$ to select significantly regulated APA events. GO analysis (http://www. geneontology.org) were carried out using Fisher's exact test. IPA analysis was carried out using default values (www.qiagen. com/ingenuity). Features of introns with regulated pAs were based on RefSeq annotations. 5'SS and 3'SS scores were based on the maximum entropy method [73].

\section{Analysis of endogenous $m R N A$ s or APA isoforms abundance}

Nuclear RNA was purified from different cell lines using the RNeasy Mini Kit (Qiagen) according to the manufacturer's directions. RNA concentrations of the samples obtained under different conditions were equalized. Equivalent amounts of purified RNA $(2 \mu \mathrm{g})$ were used as a template to synthesize cDNA using either random hexamer primers or oligo-d(T) primers and GoScript reverse transcriptase (Promega, Madison, WI, USA) according to the manufacturer's protocol. PCR was performed using the reverse transcriptase products and Taqman master mix (Applied Biosystems, Foster City, CA, USA). The primers used to detect intron/full-length and distal/proximal mRNA isoforms are described in Supplementary Table S3. Commercially available primers for GAPDH (Applied Biosystems) were used in the $\mathrm{qRT}-\mathrm{PCR}$ reactions to normalize qRT-PCR reactions. SYBR green master mix (Applied Biosystems) was used in the $\mathrm{qRT}-\mathrm{PCR}$ reactions. Relative levels were calculated using $\Delta \mathrm{C} \tau$ method. Genomic DNA was prepared from HCT116 cells as in ref. 74. For detection of second introns the following primers were used: POLR2A: forward primer 5'-GGGAAGCAGGCTGGAATTGG-3', reverse primer 5'-GTCTGCATTGTACGGAGTT-GTC-3'. CDKN1A: forward primer 5'-GAGTGGACGTTCCCCGA GTT-3', reverse primer 5'-GTCAGCCAGGCCAAGAAGA AG-3'. Ephrin B2: forward primer 5'-GCCAGGAAGGAG GTATAATTGGG-3', reverse primer: 5'-ACCTTTCTTCTC CCCTGCTAC-3'.

\section{Depletion and overexpression of $U 1 \operatorname{sn} R N A$}

HCT116 cells were transfected with either $10 \mathrm{nmol}$ of control oligo or U1 snRNA targeting morpholino oligonucleotides according to the manufacturer's instructions (Gene Tools, Philomath, OR, USA) using scrape delivery method. After addition of morpholino nucleotides, cells were scraped and transferred to a new six-well plate. The plasmid overexpressing U1 snRNA was kindly provided by Dr Gunderson (Rutgers University). HCT116 cells were transfected with this plasmid using Lipofectamine 2000 (Invitrogen, Carlsbad, CA, USA) according to the manufacturer's instructions. Cells were harvested $48 \mathrm{~h}$ after transfection and nuclear RNA was isolated. cDNA was prepared and used in $\mathrm{qRT}-\mathrm{PCR}$ reactions as described above.

\section{Nuclear extract preparation}

After UV treatment, nuclear extracts were prepared from harvested cells essentially as described $[30,32]$.

\section{Cell death ELISA assay}

Fragmentation of DNA after induction of apoptosis was determined by photometric enzyme immunoassay (Cell Death Detection ELISAPLUS; Roche, Indianapolis, IN, USA) as recommended by the manufacturer.

\section{Availability of supporting data}

The data sets supporting the results of this article are available in the NCBI's Sequence Read Archive: http://www. ncbi.nlm.nih.gov/geo/query/acc.cgi?acc=GSE71801.

\section{Conflict of Interest}

The authors declare no conflict of interest.

\section{Acknowledgements}

We thank Dr Gunderson for U1 snRNA-encoding plasmids. This work is supported by National Institute of Health grants R21 CA175794-02 to FEK and R01 GM084089 to BT.

\section{References}

1 Zhao J, Hyman L, Moore C. Formation of mRNA 3' ends in eukaryotes: mechanism, regulation, and interrelationships with other steps in mRNA synthesis. Microbiol Mol Biol Rev 1999; 63: 405-445.

2 Shatkin AJ, Manley JL. The ends of the affair: capping and polyadenylation. Nat Struct Biol 2000; 7: 838-842.

3 Shi Y, Di Giammartino DC, Taylor D et al. Molecular architecture of the human pre-mRNA 3' processing complex. Mol Cell 2009; 33: 365-376.

4 Tian B, Graber JH. Signals for pre-mRNA cleavage and polyadenylation. Wiley Interdiscip Rev RNA 2012; 3: 385-396.

5 Gunderson SI, Polycarpou-Schwarz M, Mattaj IW. U1 snRNP inhibits pre-mRNA polyadenylation through a direct interaction between U1 $70 \mathrm{~K}$ and poly(A) polymerase. Mol Cell 1998; 1: 255-264.

6 Ashe MP, Furger A, Proudfoot NJ. Stem-loop 1 of the U1 snRNP plays a critical role in the suppression of HIV-1 polyadenylation. RNA 2000; 6: 170-177.

7 Vagner S, Ruegsegger U, Gunderson SI, Keller W, Mattaj IW. Position-dependent inhibition of the cleavage step of pre-mRNA 3'-end processing by U1 snRNP. RNA 2000; 6: 178-188.

8 Kaida D, Berg MG, Younis I et al. U1 snRNP protects premRNAs from premature cleavage and polyadenylation. Nature 2010; 468: 664-668.

9 Berg MG, Singh LN, Younis I et al. U1 snRNP determines mRNA length and regulates isoform expression. Cell 2012; 150: 53-64.

10 Martinson $\mathrm{HG}$. An active role for splicing in 3'-end formation. Wiley Interdiscip Rev RNA 2011; 2: 459-470.

11 Tian B, Hu J, Zhang H, Lutz CS. A large-scale analysis of mRNA polyadenylation of human and mouse genes. Nucleic Acids Res 2005; 33: 201-212. 
12 Wang ET, Sandberg R, Luo $\mathrm{S}$ et al. Alternative isoform regulation in human tissue transcriptomes. Nature 2008; 456: $470-476$.

13 Zhang H, Lee JY, Tian B. Biased alternative polyadenylation in human tissues. Genome Biol 2005; 6: R100.

14 Sandberg R, Neilson JR, Sarma A, Sharp PA, Burge CB. Proliferating cells express mRNAs with shortened $3^{\prime}$ untranslated regions and fewer microRNA target sites. Science 2008; 320: 1643-1647.

15 Ji Z, Lee JY, Pan Z, Jiang B, Tian B. Progressive lengthening of 3' untranslated regions of mRNAs by alternative polyadenylation during mouse embryonic development. Proc Natl Acad Sci USA 2009; 106: 7028-7033.

16 Flavell SW, Kim TK, Gray JM et al. Genome-wide analysis of MEF2 transcriptional program reveals synaptic target genes and neuronal activity-dependent polyadenylation site selection. Neuron 2008; 60: 1022-1038.

17 Hoque M, Ji Z, Zheng D et al. Analysis of alternative cleavage and polyadenylation by 3 ' region extraction and deep sequencing. Nat Methods 2013; 10: 133-139.

18 Hall-Pogar T, Liang S, Hague LK, Lutz CS. Specific transacting proteins interact with auxiliary RNA polyadenylation elements in the COX-2 3'-UTR. RNA 2007; 13: 1103-1115.

19 Lutz CS. Alternative polyadenylation: a twist on mRNA 3' end formation. ACS Chem Biol 2008; 3: 609-617.

20 Lutz CS, Moreira A. Alternative mRNA polyadenylation in eukaryotes: an effective regulator of gene expression. Wiley Interdiscip Rev RNA 2001; 2: 23-31.

$21 \mathrm{Li} \mathrm{W}$, You B, Hoque $\mathrm{M}$ et al. Systematic profiling of poly (A)+ transcripts modulated by core 3 ' end processing and splicing factors reveals regulatory rules of alternative cleavage and polyadenylation. PLoS Genet 2015; 23: 11.

22 Ljungman M, Zhang F, Chen F, Rainbow AJ, McKay BC. Inhibition of RNA polymerase II as a trigger for the p53 response. Oncogene 1999; 18: 583-592.

23 Hanawalt PC, Donahue BA, Sweder KS. Repair and transcription: collision or collusion? Curr Biol 1994; 4: 518-521.

24 Donahue BA, Yin S, Taylor JS, Reines D, Hanawalt PC. Transcript cleavage by RNA polymerase II arrested by a cyclobutane pyrimidine dimer in the DNA template. Proc Natl Acad Sci USA 1994; 91: 8502-8506.

25 Kleiman FE, Manley JL. The BARD1-CstF-50 interaction links mRNA 3' end formation to DNA damage and tumor suppression. Cell 2001; 104: 743-753.

26 Decorsiere A, Cayrel A, Vagner S, Millevoi S. Essential role for the interaction between hnRNP H/F and a $\mathrm{G}$ quadruplex in maintaining p53 pre-mRNA 3'-end processing and function during DNA damage. Genes Dev 2011; 25: 220-225.

27 Kleiman FE, Manley JL. Functional interaction of BRCA1-associated BARD1 with polyadenylation factor CstF-50. Science 1999; 285: 1576-1579.

28 Kleiman FE, Wu-Baer F, Fonseca D, Kaneko S, Baer R, Manley JL. BRCA1/BARD1 inhibition of mRNA 3' processing involves targeted degradation of RNA polymerase II. Genes Dev 2005; 19: 1227-1237.
29 Mirkin N, Fonseca D, Mohammed S, Cevher MA, Manley JL, Kleiman FE. The 3' processing factor CstF functions in the DNA repair response. Nucleic Acids Res 2008; 36: 1792-1804.

30 Cevher MA, Zhang X, Fernandez S et al. Nuclear deadenylation/polyadenylation factors regulate 3 ' processing in response to DNA damage. EMBO J 2010; 29: 1674-1687.

31 Cevher MA, Kleiman FE.. Connections between 3'-end processing and DNA damage response. Wiley Interdiscip Rev RNA 2010; 1: 193-199.

32 Nazeer FI, Devany E, Mohammed S et al. p53 inhibits mRNA 3' processing through its interaction with the CstF/BARD1 complex. Oncogene 2011; 30: 3073-3083.

33 Devany E, Zhang X, Park JY, Tian B, Kleiman FE. Positive and negative feedback loops in the p53 and mRNA 3' processing pathways. Proc Natl Acad Sci USA 2013; 110: 3351-3356.

34 Zhang X, Devany E, Murphy MR, Glazman G, Persaud M, Kleiman FE. PARN deadenylase is involved in miRNA-dependent degradation of TP53 mRNA in mammalian cells. Nucleic Acids Res 2015; 43: 10925-10938.

35 Tian B, Pan Z, Lee JY. Widespread mRNA polyadenylation events in introns indicate dynamic interplay between polyadenylation and splicing. Genome Res 2007; 17: 156-165.

36 Folco EG, Coil KE, Reed R. The anti-tumor drug E7107 reveals an essential role for SF3b in remodeling U2 snRNP to expose the branch point-binding region. Genes Dev 2011; 25: $440-444$.

37 Sundaramoorthy S, Vázquez-Novelle MD, Lekomtsev S, Howell M, Petronczki M. Functional genomics identifies a requirement of pre-mRNA splicing factors for sister chromatid cohesion. EMBO J 2014; 33: 2623-2642.

38 Smith JS, Tachibana I, Pohl U et al. A transcript map of the chromosome 19q-arm glioma tumor suppressor region. Genomics 2000; 64: 44-50.

39 Hou J, Li X, Li C et al. Plasma membrane gp96 enhances invasion and metastatic potential of liver cancer via regulation of uPAR. Mol Oncol 2015; 9: 1312-1323.

40 Garcia TX, Hofmann MC. NOTCH signaling in Sertoli cells regulates gonocyte fate. Cell Cycle 2013; 12: 2538-2545.

41 Vermezovic J, Adamowicz M, Santarpia L et al. Notch is a direct negative regulator of the DNA-damage response. Nat Struct Mol Biol 2015; 22: 417-424.

42 Ma J, Yu X, Guo L, Lu SH. DUSP6, a tumor suppressor, is involved in differentiation and apoptosis in esophageal squamous cell carcinoma. Oncol Lett 2013; 6: 1624-1630.

43 Bagnyukova TV, Restifo D, Beeharry N et al. DUSP6 regulates drug sensitivity by modulating DNA damage response. Br J Cancer 2013; 109: 1063-1071.

44 Garner E, Raj K. Protective mechanisms of p53-p21-pRb proteins against DNA damage-induced cell death. Cell Cycle 2008; 7: 277-282.

45 Prives C, Gottifredi V. The p21 and PCNA partnership: a new twist for an old plot. Cell Cycle 2008; 7: 3840-3846.

46 Yao J, Ardehali MB, Fecko CJ, Webb WW, Lis JT. Intranuclear distribution and local dynamics of RNA polymerase II during transcription activation. Mol Cell 2007; 28: 978-990. 
47 Heine GF, Horwitz AA, Parvin JD. Multiple mechanisms contribute to inhibit transcription in response to DNA damage. J Biol Chem 2008; 283: 9555-9561.

48 Wang HU, Chen ZF, Anderson DJ. Molecular distinction and angiogenic interaction between embryonic arteries and veins revealed by ephrin-B2 and its receptor Eph-B4. Cell 1998; 93: 741-753.

49 Genander M, Frisen J. Ephrins and Eph receptors in stem cells and cancer. Curr Opin Cell Biol 2010; 22: 611-616.

50 Tort F, Bartkova J, Sehested M, Orntoft T, Lukas J, Bartek J. Retinoblastoma pathway defects show differential ability to activate the constitutive DNA damage response in human tumorigenesis. Cancer Res 2006; 66: 10258-10263.

51 Qi JJ, Liu L, Cao JX et al. E2F1 regulates p53R2 gene expression in p53-deficient cells. Mol Cell Biochem 2015; 399: 179-188.

52 Preker P, Nielsen J, Kammler S et al. RNA exosome depletion reveals transcription upstream of active human promoters. Science 2008; 322: 1851-1854.

$53 \mathrm{Li} \mathrm{W}$, You B, Hoque M et al. Systematic profiling of poly (A) + transcripts modulated by core 3 ' end processing and splicing factors reveals regulatory rules of alternative cleavage and polyadenylation. PLoS Genet 2015; 11: e1005166.

54 Calicchio ML, Collins T, Kozakewich HP. Identification of signaling systems in proliferating and involuting phase infantile hemangiomas by genome-wide transcriptional profiling. Am J Pathol 2009; 174: 1638-1649.

55 Shinawi M, Erez A, Shardy DL et al. Syndromic thrombocytopenia and predisposition to acute myelogenous leukemia caused by constitutional microdeletions on chromosome 21q. Blood 2008; 112: 1042-1047.

56 Eliceiri GL, Smith JH. Sensitivity to UV radiation of small nuclear RNA synthesis in mammalian cells. Mol Cell Biol 1983; 3: 2151-2155.

57 Spraggon L, Cartegni L. U1 snRNP-dependent suppression of polyadenylation: physiological role and therapeutic opportunities in cancer. Int J Cell Biol 2013; 2013: 846510.

58 McKay BC. Post-transcriptional regulation of DNA damage-responsive gene expression. Antioxid Redox Signal 2014; 20: 640-654.

59 Freeman JA, Espinosa JM. The impact of posttranscriptional regulation in the p53 network. Brief Funct Genomics 2013; 12: 46-57.

60 Bregman DB, Halaban R, van Gool AJ, Henning KA, Friedberg EC, Warren SL. UV-induced ubiquitination of RNA polymerase II: a novel modification deficient in Cockayne syndrome cells. Proc Natl Acad Sci USA 1996; 93: $11586-11590$.

61 Ratner JN, Balasubramanian B, Corden J, Warren SL, Bregman DB. Ultraviolet radiation-induced ubiquitination and proteasomal degradation of the large subunit of RNA polymerase II. Implications for transcription-coupled DNA repair. J Biol Chem 1998; 273: 5184-5189.

62 Mitsui A, Sharp PA. Ubiquitination of RNA polymerase II large subunit signaled by phosphorylation of carboxyl- terminal domain. Proc Natl Acad Sci USA 1999; 96: 6054-6059.

63 Starita LM, Horwitz AA, Keogh MC, Ishioka C, Parvin JD, Chiba N. BRCA1/BARD1 ubiquitinate phosphorylated RNA polymerase II. J Biol Chem 2005; 280: 24498-24505.

$64 \mathrm{Yu} \mathrm{L}$, Volkert MR. UV damage regulates alternative polyadenylation of the RPB2 gene in yeast. Nucleic Acids Res 2013; 41: 3104-3114.

65 Espinosa JM, Verdun RE, Emerson BM. p53 functions through stress- and promoter-specific recruitment of transcription initiation components before and after DNA damage. Mol Cell 2003; 12: 1015-1027.

66 Gomes NP, Bjerke G, Llorente B, Szostek SA, Emerson BM, Espinosa JM. Gene-specific requirement for $\mathrm{P}-\mathrm{TEFb}$ activity and RNA polymerase II phosphorylation within the p53 transcriptional program. Genes Dev 2006; 20: $601-612$.

67 Donner AJ, Szostek S, Hoover JM, Espinosa JM. CDK8 is a stimulus-specific positive coregulator of p53 target genes. Mol Cell 2007; 27: 121-133.

68 Oda K, Arakawa H, Tanaka T et al. p53AIP1, a potential mediator of p53-dependent apoptosis, and its regulation by Ser-46-phosphorylated p53. Cell 2000; 102: 849-862.

69 Tang Y, Luo J, Zhang W, Gu W. Tip60-dependent acetylation of p53 modulates the decision between cell-cycle arrest and apoptosis. Mol Cell 2006; 24: 827-839.

70 Flores ER, Tsai KY, Crowley D et al. p63 and p73 are required for, p53-dependent apoptosis in response to DNA damage. Nature 2002; 416: 560-564.

71 Samuels-Lev Y, O'Connor DJ, Bergamaschi D et al. ASPP proteins specifically stimulate the apoptotic function of p53. Mol Cell 2001; 8: 781-794.

72 Langmead B, Salzberg SL. Fast gapped-read alignment with Bowtie 2. Nat Methods 2012; 9: 357-359.

73 Yeo G, Burge CB. Maximum entropy modeling of short sequence motifs with applications to RNA splicing signals. J Comput Biol 2004; 11: 377-394.

74 Kleiman FE, Ramírez AO, Dodelson de Kremer R, Gravel RA, Argaraña CE. A frequent TG deletion near the polyadenylation signal of the human HEXB gene: occurrence of an irregular DNA structure and conserved nucleotide sequence motif in the $3^{\prime}$ untranslated region. Hum Mutat 1998; 12: 320-329.

(Supplementary information is linked to the online version of the paper on the Cell Discovery website.)

This work is licensed under a Creative Commons Attribution 4.0 International License. The images or other third party material in this article are included in the article's Creative Commons license, unless indicated otherwise in the credit line; if the material is not included under the Creative Commons license, users will need to obtain permission from the license holder to reproduce the material. To view a copy of this license, visit http://creativecommons.org/licenses/by/4.0/ 